\title{
Progression of Metabolic Acidosis in Chronic Kidney Disease
}

\author{
Masayuki Tanemoto ${ }^{a, b}$ \\ ${ }^{a}$ Department of Internal Medicine, Shin-Kuki General Hospital, Kuki, Japan; ${ }^{b}$ Division of Nephrology, Department of \\ Internal Medicine, International University of Health and Welfare School of Medicine, Atami, Japan
}

\section{Keywords}

Acid-base disorder - Chronic kidney disease - Disease progression · Kidney failure $\cdot$ Metabolic acidosis

\begin{abstract}
Background: Metabolic acidosis, which is classified into either high anion gap type (high-AGMA) or non-anion gap type (non-AGMA), is a common complication in chronic kidney disease (CKD), but its development in CKD is obscure. Methods: Records of venous blood gas at a general hospital (2015-2017) were assessed by the physiological approach. Excluding records of primary respiratory disturbances, parameters of high-AGMA and non-AGMA ( $\triangle \mathrm{AG}$ and $\Delta \Delta$, respectively) were compared with the estimated glomerular filtration rate (eGFR). Results: $\triangle A G$ correlated with eGFR negatively $(r=-0.397, p<0.001)$, but $\Delta \Delta$ did not correlate with eGFR $(p=0.51)$. Among the records grouped by the CKD stage (either G1-3, G4, or G5), $\triangle$ AG in G5 $(0.9 \pm 2.7)$ was higher than those in G1-3 $(-2.2 \pm 2.6, p<0.001)$ and in G4 $(-2.0$ $\pm 2.1, p<0.001) . \Delta \Delta$ in $\mathrm{G} 4(4.0 \pm 4.1)$ was higher than that in $\mathrm{G} 1-3(1.5 \pm 3.7, p=0.056)$. Between the subgroups in $\mathrm{G} 5$ (either G5a: eGFR 10-15, G5b: eGFR 5-10, or G5c: eGFR <5 mL/ $\left.\mathrm{min} / 1.73 \mathrm{~m}^{2}\right), \triangle A G$ in $\mathrm{G} 5 \mathrm{c}(3.8 \pm 2.1)$ was higher than that in $\mathrm{G} 5 \mathrm{~b}(0.8 \pm 2.4, p<0.001)$, which was higher than that in $\mathrm{G} 5 \mathrm{a}$ $(-0.9 \pm 1.8, p<0.001) . \Delta \Delta$ in $\mathrm{G} 5 a(5.6 \pm 4.1)$ was higher than those in $\mathrm{G} 4(p=0.041)$ and in $\mathrm{G} 5 \mathrm{~b}(3.2 \pm 3.9, p=0.001)$, which
\end{abstract}

\begin{tabular}{ll}
\hline KARGER & ( 2019 The Author(s) \\
Published by S. Karger AG, Basel & Karger \\
E-Mail karger@karger.com & This article is licensed under the Creative Commons Attribution- \\
www.karger.com/kdd & $\begin{array}{l}\text { NonCommercial-NoDerivatives 4.0 International License (CC BY- } \\
\text { NC-ND) (http://www.karger.com/Services/OpenAccessLicense). } \\
\text { Usage and distribution for commercial purposes as well as any dis- } \\
\text { tribution of modified material requires written permission. }\end{array}$
\end{tabular}

was higher than that in $\mathrm{G} 5 \mathrm{c}(0.8 \pm 3.8, p=0.006)$. Conclusion: High-AGMA developed and progressed in CKD stage G5. Non-AGMA generally progressed before the early phase of CKD stage $\mathrm{G} 5$ and regressed thereafter.

(c) 2019 The Author(s)

Published by S. Karger AG, Basel

\section{Introduction}

Metabolic acidosis, a group of acid-base disorders with decreases in serum bicarbonate concentration $\left(\mathrm{HCO}_{3}{ }^{-}\right)$, is classified into either high anion gap type (highAGMA), where accumulation of titratable acid decreases $\mathrm{HCO}_{3}{ }^{-}$, or non-anion gap type (non-AGMA), where accumulation of chloride $\left(\mathrm{Cl}^{-}\right)$decreases $\mathrm{HCO}_{3}{ }^{-}[1,2]$. The kidney participates in the pathophysiology of both highAGMA and non-AGMA [3, 4]. It filters bicarbonate at the glomeruli and reabsorbs it at the renal tubules. It also filters titratable acid at the glomeruli and excretes ammonium at the renal tubules. Thus, both high-AGMA and non-AGMA develop by renal dysfunction, and metabolic acidosis is a common complication in chronic kidney disease (CKD) $[5,6]$.

Adversely affecting several organs, metabolic acidosis associates with mortality in CKD $[7,8]$. Amelioration of metabolic acidosis slows CKD progression $[9,10]$. However, there is inadequate information on the development 
and progression of metabolic acidosis in CKD [3-6, 8, 11]. In the present study, development and progression of high-AGMA and non-AGMA were examined by using clinical records of blood gas analysis.

\section{Materials and Methods}

\section{Design and Setting}

This study was a retrospective analysis of clinical records at a general hospital in a metropolitan suburb. Records of patients managed in the Department of Nephrology from April 2015 to September 2017 were reviewed. The data of venous blood gas analysis performed simultaneously with measurement of serum concentrations of sodium $\left(\mathrm{Na}^{+}\right), \mathrm{Cl}^{-}$, albumin (Alb), and creatinine $(\mathrm{Cr})$ were collected from the records. The records of either primary respiratory acidosis $\left(\mathrm{pH}<7.36\right.$ and $\mathrm{pCO}_{2}>48 \mathrm{~mm} \mathrm{Hg}$ ) or primary respiratory alkalosis $\left(\mathrm{pH}>7.38\right.$ and $\mathrm{pCO}_{2}<43 \mathrm{~mm} \mathrm{Hg}$ ) were excluded. The study was approved by the Ethics Committee of the hospital.

\section{Laboratory Measurement and Definition}

Blood gas analysis, which includes measurement of $\mathrm{pH}$, $\mathrm{HCO}_{3}{ }^{-}$, and lactate concentration (Lac), was performed by the GEM premier 4000 analyzer (Instrumentation Laboratory Company, MA, USA). Serum chemistry measurement was performed by the TBA-c8000 analyzer (Canon Medical Systems, Tochigi, Japan). Estimated glomerular filtration rate (eGFR) was calculated from $\mathrm{Cr}$, age, and gender by a modified Modification of Diet in Renal Disease Study equation [12].

Anion gap (AG) was calculated as "AG $=\mathrm{Na}^{+}-\mathrm{Cl}^{-}-\mathrm{HCO}_{3}{ }^{-}$" $[1,2]$. Based on the finding that $1 \mathrm{~g} / \mathrm{dL}$ Alb accounts for a negative charge of $2.5 \mathrm{mEq} / \mathrm{L}$ [13-15], AG was adjusted by $\mathrm{Alb}\left(\mathrm{AG}_{\mathrm{adj}}\right)$ as " $\mathrm{AG}_{\mathrm{adj}}=\mathrm{AG}+2.5 \times(4-\mathrm{Alb})$." Average value of $\mathrm{AG}_{\mathrm{adj}}$ in the records with neither acidemia nor alkalemia ( $\mathrm{pH} 7.36-38)$ was used as its reference $\left(\mathrm{AG}_{\mathrm{ref}}\right)$, and $25 \mathrm{mmol} / \mathrm{L}$ was used as the reference of $\mathrm{HCO}_{3}^{-}\left(\mathrm{HCO}_{3}^{-}{ }^{-}\right.$ref $)[1]$.

\section{Diagnosis of Metabolic Acidosis}

By using $\mathrm{HCO}_{3}{ }^{-}$ref and $\mathrm{AG}_{\text {ref, }}$, metabolic acidosis was diagnosed according to the physiological approach $[1,2]$. High-AGMA excluding lactic acidosis was diagnosed by using $A G_{\text {adj }}$; the $A G_{\text {adj }}$ subtracted by $A_{\text {ref }}$ and Lac $(\triangle A G)$ was used to indicate the magnitude of high-AGMA. $\triangle \mathrm{AG}>0$ was used to indicate the existence of the High-AGMA excluding lactic acidosis. Non-AG was diagnosed by using $\mathrm{HCO}_{3}{ }^{-}$ref; $\mathrm{HCO}_{3}{ }^{-}$ref was subtracted by $\mathrm{HCO}_{3}{ }^{-}$ $\left(\triangle \mathrm{HCO}_{3}{ }^{-}\right)$, and the value of the $\Delta \mathrm{HCO}_{3}{ }^{-}$subtracted by $\triangle \mathrm{AG}(\Delta \Delta)$ was used to indicate the magnitude of non-AGMA. $\Delta \Delta>0$ was used to indicate the existence of non-AGMA.

\section{Statistical Analysis}

Continuous variables were calculated as the mean \pm SD and were compared using analysis of variance. A correlation between parameters was analyzed using Pearson's correlation test. A linear regression between parameters was also built, and $r$ of the prediction model was obtained. All statistical analyses were performed using SPSS software package (IBM Corp., Armonk, NY, USA). A $p$ value of $<0.01$ was considered statistically significant.
Table 1. Laboratory measures and calculated parameters of records

\begin{tabular}{lc}
\hline Measure & $n=269$ \\
\hline $\mathrm{pH}$ & $7.31 \pm 0.06$ \\
$\mathrm{pCO}_{2}, \mathrm{~mm} \mathrm{Hg}$ & $42.6 \pm 4.6$ \\
Bicarbonate, $\mathrm{mmol} / \mathrm{L}$ & $21.6 \pm 4.0$ \\
Sodium, $\mathrm{mmol} / \mathrm{L}$ & $139.5 \pm 3.8$ \\
Chloride, $\mathrm{mmol} / \mathrm{L}$ & $107.7 \pm 5.4$ \\
Albumin, g/dL & $3.45 \pm 0.73$ \\
Creatinine, $\mathrm{mg} / \mathrm{dL}$ & $5.18 \pm 2.79$ \\
Lactate, $\mathrm{mmol} / \mathrm{L}_{\mathrm{eGFR}, \mathrm{mL} / \mathrm{min} / 1.73 \mathrm{~m}^{2}}$ & $1.28 \pm 0.99$ \\
$\mathrm{AG}{ }_{\mathrm{adj}}$ & $14.1 \pm 15.3$ \\
$\Delta \mathrm{AG}$ & $11.6 \pm 3.1$ \\
$\Delta \mathrm{HCO}_{3}{ }^{-}, \mathrm{mmol} / \mathrm{L}$ & $0.1 \pm 2.9$ \\
$\Delta \Delta$ & $3.4 \pm 4.0$ \\
\end{tabular}

Data are presented as mean $\pm \mathrm{SD}$. $\mathrm{AG}_{\mathrm{adj}}$, anion gap adjusted by albumin; eGFR, estimated glomerular filtration rate; $\triangle \mathrm{AG}, \mathrm{AG}_{\text {adj }}$ subtracted by its reference and lactate; $\Delta \mathrm{HCO}_{3}{ }^{-}$, bicarbonate subtracted from its reference; $\Delta \Delta, \Delta \mathrm{HCO}_{3}{ }^{-}$subtracted by $\Delta \mathrm{AG}$.

\section{Results}

\section{Laboratory Measures and Calculated Parameters}

Overall, 269 records were included in the study. Fiftyone records had $\mathrm{pH} 7.36-7.38$, and the average value of $A G_{\text {adj }}$ among them was 10.2. Table 1 shows the summary of laboratory measures and calculated parameters in them; $\mathrm{pH}, \mathrm{pCO}_{2}, \mathrm{HCO}_{3}{ }^{-}$, Lac, and $\mathrm{Cr}$ ranged from 7.10 to 7.45 , from 26 to $54 \mathrm{~mm} \mathrm{Hg}$, from 9.9 to $34.2 \mathrm{mmol} / \mathrm{L}$, from 0.5 to $11.7 \mathrm{mmol} / \mathrm{L}$, and from 0.27 to $13.05 \mathrm{mg} / \mathrm{dL}$, respectively. eGFR, $\mathrm{AG}_{\mathrm{adj}}$, and $\triangle \mathrm{HCO}_{3}{ }^{-}$ranged from 2.6 to $165.6 \mathrm{~mL} / \mathrm{min} / 1.73 \mathrm{~m}^{2}$, from 4.8 to 24.6 , and -9.2 to $15.1 \mathrm{mmol} / \mathrm{L}$, respectively. $\Delta \mathrm{AG}$ and $\Delta \Delta$ ranged from -6.7 to 8.6 and from -9.7 to 16.8 , respectively.

\section{Development of Metabolic Acidosis in CKD}

Figure 1 shows correlations of $\mathrm{HCO}_{3}{ }^{-}, \Delta \mathrm{AG}$, and $\Delta \Delta$ with eGFR. There was a positive correlation between eGFR and $\mathrm{HCO}_{3}{ }^{-}(r=0.333, p<0.001$; Fig. 1a) and a negative correlation between eGFR and $\triangle \mathrm{AG}(r=-0.397$, $p<0.001$; Fig. 1b), but there was no correlation between eGFR and $\Delta \Delta(r=-0.040, p=0.51$; Fig. 1c). There were negative correlations between $\triangle \mathrm{AG}$ and $\mathrm{HCO}_{3}{ }^{-}(r=$ $-0.289, p<0.001$; Fig. 2a) and between $\Delta \Delta$ and $\mathrm{HCO}_{3}{ }^{-}$ $(r=-0.747, p<0.001$; Fig. 2b).

The records were grouped by the CKD stage (either G1-3: eGFR $\geq 30 \mathrm{~mL} / \mathrm{min} / 1.73 \mathrm{~m}^{2}$, G4: eGFR $15-30 \mathrm{~mL} /$ $\mathrm{min} / 1.73 \mathrm{~m}^{2}$, or G5: eGFR $<15 \mathrm{~mL} / \mathrm{min} / 1.73 \mathrm{~m}^{2}$ ), and the
Tanemoto 


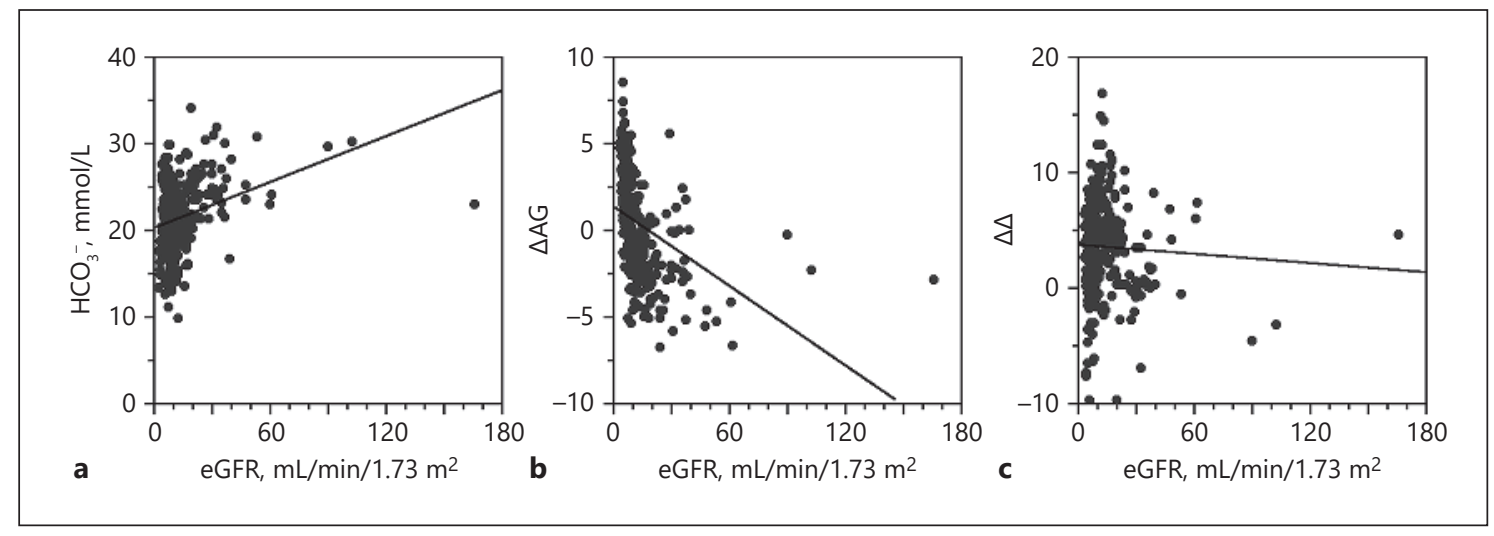

Fig. 1. Scatter plots comparing $\mathrm{HCO}_{3}^{-}(\mathbf{a}), \Delta \mathrm{AG}(\mathbf{b})$, and $\Delta \Delta$ (c) with eGFR. There was a positive correlation between eGFR and $\mathrm{HCO}_{3}{ }^{-}(r=0.333, p<0.001)$ with a linear approximation of $y=0.087 x+20.4(\mathbf{a})$ and a negative correlation between eGFR and $\triangle \mathrm{AG}(r=-0.397, p<0.001)$ with a linear approximation of $y=-0.076 x+1.13(\mathbf{b})$. c There was no correlation between eGFR and $\Delta \Delta(r=-0.040, p=0.51)$. eGFR, estimated glomerular filtration rate; $\mathrm{HCO}_{3}{ }^{-}$, bicarbonate concentration; $\triangle \mathrm{AG}, \mathrm{AG}_{\text {adj }}$ subtracted by its reference and lactate; $\Delta \Delta, \mathrm{HCO}_{3}{ }^{-}$reference subtracted by $\mathrm{HCO}_{3}{ }^{-}$and $\triangle \mathrm{AG}$.

Fig. 2. Scatter plots comparing $\triangle \mathrm{AG}$ (a) and $\Delta \Delta$ (b) with $\mathrm{HCO}_{3}{ }^{-}$. There were negative correlations between $\triangle \mathrm{AG}$ and $\mathrm{HCO}_{3}{ }^{-}$ $(r=-0.289, p<0.001)$ with a linear approximation of $y=-0.395 x-21.6(\mathbf{a})$ and between $\Delta \Delta$ and $\mathrm{HCO}_{3}^{-}(r=-0.747, p<$ 0.001 ) with a linear approximation of $y=$ $-0.708 x-24.0+$ (b). $\mathrm{HCO}_{3}{ }^{-}$, bicarbonate concentration; $\triangle \mathrm{AG}, \mathrm{AG}_{\mathrm{adj}}$ subtracted by its reference and lactate; $\triangle \Delta, \mathrm{HCO}_{3}{ }^{-}$reference subtracted by $\mathrm{HCO}_{3}{ }^{-}$and $\triangle \mathrm{AG}$.

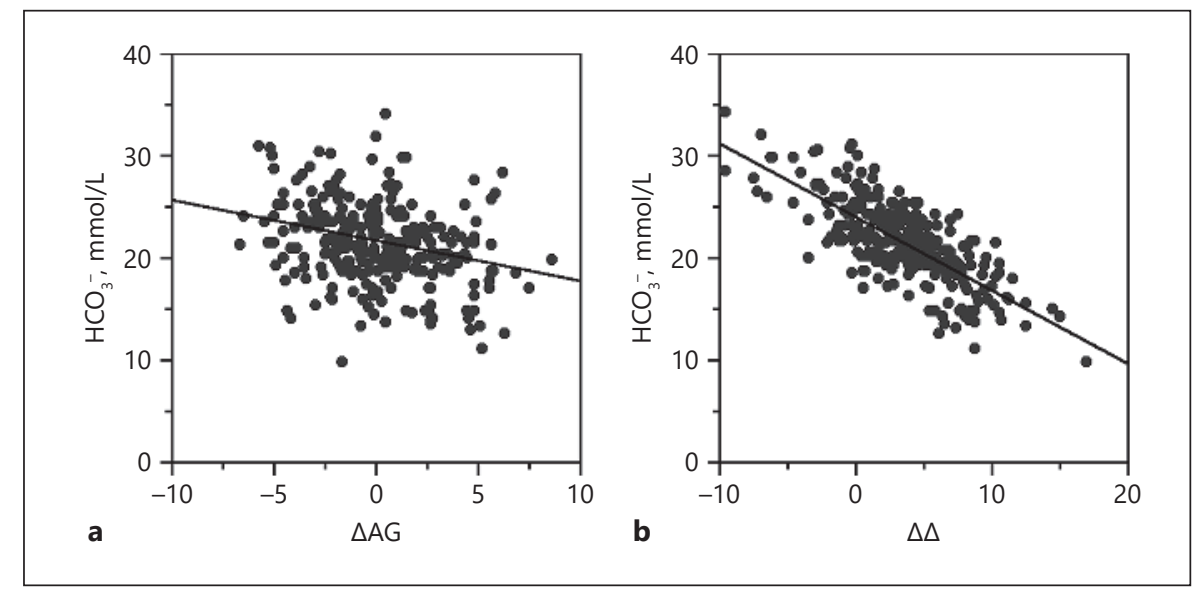

levels of $\mathrm{HCO}_{3}{ }^{-}, \Delta \mathrm{AG}$, and $\Delta \Delta$ were compared between the groups (Table 2). The levels of $\mathrm{HCO}_{3}{ }^{-}$in $\mathrm{G} 5$ were significantly lower than those in G1-3 and in G4 $(p<0.001$ between G5 and G1-3 and between G5 and G4). The levels in G4 were generally lower than those in G1-3 ( $p=$ 0.012 ). The levels of $\triangle \mathrm{AG}$ in $\mathrm{G} 5$ were significantly higher than those in G1-3 and in G4 ( $p<0.001$ between G5 and G1-3 and between G5 and G4). However, the levels in G4 were not significantly different from those in G1-3 ( $p=$ $0.93)$. Although the levels of $\Delta \Delta$ were not significantly different between G1-3, G4, and G5 ( $p=0.056,0.12$, and 0.65 between G1-3 and G4, between G1-3 and G5, and between G4 and G5, respectively), its levels in G4 were generally higher than those in G1-3.
The records of G5 were further grouped by eGFR (either G5a: eGFR $10-15 \mathrm{~mL} / \mathrm{min} / 1.73 \mathrm{~m}^{2}$, G5b: eGFR 5-10 $\mathrm{mL} / \mathrm{min} / 1.73 \mathrm{~m}^{2}$, or G5c: eGFR $<5 \mathrm{~mL} / \mathrm{min} / 1.73 \mathrm{~m}^{2}$ ), and the levels of $\mathrm{HCO}_{3}{ }^{-}, \Delta \mathrm{AG}$, and $\Delta \Delta$ were compared between these subgroups (Table 3). The levels of $\mathrm{HCO}_{3}{ }^{-}$ were not significantly different between the subgroups ( $p=0.52,0.99$, and 0.62 between G5a and G5b, between G5a and G5c, and between G5b and G5c, respectively). The levels of $\triangle A G$ in $G 5 c$ were significantly higher than those in G5b and in G5a, and its levels in G5b were significantly higher than those in G5a $(p<0.001$ between G5c and G5b, between G5c and G5a, and between G5b and G5a). The levels of $\Delta \Delta$ in G5a were generally higher than those in G4 $(p=0.041)$. However, in contrast to the 
Table 2. Comparison of $\mathrm{HCO}_{3}{ }^{-}, \Delta \mathrm{AG}$, and $\Delta \Delta$ between the CKD stages

\begin{tabular}{llllr}
\hline Measure & \multicolumn{2}{l}{ CKD stage } & \multirow{2}{*}{$p$ value } \\
\cline { 2 - 4 } & $\begin{array}{l}\mathrm{G} 1-3 \\
(n=23)\end{array}$ & $\begin{array}{l}\mathrm{G} 4 \\
(n=55)\end{array}$ & $\begin{array}{l}\mathrm{G} 5 \\
(n=191)\end{array}$ & \\
\hline $\mathrm{HCO}_{3}{ }^{-}$ & $25.7 \pm 3.7$ & $23.1 \pm 3.9$ & $20.1 \pm 3.6$ & $<0.001$ \\
$\Delta \mathrm{AG}$ & $-2.2 \pm 2.6$ & $-2.0 \pm 2.1$ & $0.9 \pm 2.7$ & $<0.001$ \\
$\Delta \Delta$ & $1.5 \pm 3.7$ & $4.0 \pm 4.1$ & $3.4 \pm 4.3$ & 0.069 \\
\hline
\end{tabular}

Data are presented as mean $\pm \mathrm{SD}$. CKD, chronic kidney disease; $\mathrm{HCO}_{3}{ }^{-}$, bicarbonate concentration; $\triangle \mathrm{AG}$, albumin-adjusted anion gap subtracted by its reference and lactate; $\Delta \Delta, \Delta \mathrm{HCO}_{3}^{-}$(bicarbonate subtracted from its reference) subtracted by $\Delta \mathrm{AG}$.

levels of $\triangle A G$, its levels in G5b were significantly lower than those in G5a, and its levels in G5c were significantly lower than those in G5b and in G5a ( $p=0.001,0.006$, and $<0.001$ between G5b and G5a, between G5c and G5b, and between G5c and G5a, respectively).

\section{Discussion}

The present study revealed progression of metabolic acidosis in CKD. High-AGMA other than lactic acidosis developed in CKD stage G5 and progressed by a further decline of renal function in this stage. Non-AGMA generally progressed by a decline of renal function before the early phase of stage G5, but it regressed thereafter.

In the present study, an indicator of high-AGMA, $\triangle \mathrm{AG}$, had generally negative values before the early phase of stage G5 and began to present positive values thereafter. These findings support the notion that the renal ability to excrete titratable acid is preserved until renal function is impaired severely [3]. Furthermore, the present study also found that $\triangle \mathrm{AG}$ increased as renal function declined in stage G5. Thus, the findings indicated that high-AGMA other than lactic acidosis developed and progressed in CKD stage G5.

Non-AGMA is presumed to progress from the early CKD stages, since the renal ability to reabsorb bicarbonate and to excrete ammonium is impaired as renal function declines $[3,4,11]$. Supporting this notion, an indicator of non-AGMA, $\Delta \Delta$, increased gradually before the early phase of stage G5. However, $\Delta \Delta$ decreased rather than increased thereafter. These findings indicated that non-AGMA regressed rather than progressed by a renal
Table 3. Comparison of $\mathrm{HCO}_{3}{ }^{-}, \Delta \mathrm{AG}$, and $\Delta \Delta$ between the subgroups of stage G5

\begin{tabular}{lcccc}
\hline Measure & \multicolumn{2}{l}{ Subgroup; eGFR, $\mathrm{mL} / \mathrm{min} / 1.73 \mathrm{~m}^{2}$} & \multirow{2}{*}{$p$ value } \\
\cline { 2 - 4 } & $\begin{array}{l}\mathrm{G} 5 \mathrm{a} ; 10-15 \\
(n=55)\end{array}$ & $\begin{array}{l}\mathrm{G} 5 \mathrm{~b} ; 5-10 \\
(n=98)\end{array}$ & $\begin{array}{c}\mathrm{G} 5 \mathrm{c} ;<5 \\
(n=38)\end{array}$ & \\
\hline $\mathrm{HCO}_{3}{ }^{-}$ & $20.3 \pm 3.4$ & $21.0 \pm 3.8$ & $20.4 \pm 3.4$ & 0.46 \\
$\triangle \mathrm{AG}$ & $-0.9 \pm 1.8$ & $0.8 \pm 2.4$ & $3.8 \pm 2.1$ & $<0.001$ \\
$\triangle \Delta$ & $5.6 \pm 4.1$ & $3.2 \pm 3.9$ & $0.8 \pm 3.8$ & $<0.001$ \\
\hline
\end{tabular}

Data are presented as mean $\pm \mathrm{SD}$. $\mathrm{HCO}_{3}{ }^{-}$, bicarbonate concentration; $\triangle \mathrm{AG}$, albumin-adjusted anion gap subtracted by its reference and lactate; $\Delta \Delta, \Delta \mathrm{HCO}_{3}{ }^{-}$(bicarbonate subtracted from its reference) subtracted by $\triangle \mathrm{AG}$; eGFR, estimated glomerular filtration rate.

function decline in stage G5. Bicarbonate would have begun to accumulate during the progression of renal dysfunction in stage G5. The levels of $\mathrm{HCO}_{3}{ }^{-}$, which did not increase despite the $\triangle \mathrm{AG}$ increase in stage $\mathrm{G} 5$, also indicated the accumulation of bicarbonate at this stage. Severe renal impairment would decrease not only tubular reabsorption of bicarbonate but also its glomerular filtration, which would facilitate accumulation of bicarbonate in CKD stage G5.

The leading cause of lactic acidosis is tissue hypoxia, and lactic acidosis develops irrespective of CKD progression [16]. Hence, we excluded lactic acidosis as the highAGMA developing in CKD. Ketoacidosis also develops irrespective of CKD progression; diabetic ketoacidosis is the most common, followed by fasting ketoacidosis and alcoholic ketoacidosis [17]. Therefore, development of ketoacidosis might have caused the present increase in $\triangle \mathrm{AG}$ in CKD stage G5. However, it is unlikely that either diabetic, fasting, or alcoholic ketoacidosis generally developed and progressed in CKD stage G5. Thus, inclusion of ketoacidosis in the analysis of high-AG would not have significantly influenced the present finding of CKD-associated development of high-AGMA.

In the physiological approach, a time-honored tool to diagnose acid-base disturbances, increment of $A G_{\text {adj }}$ from its reference $\left(\mathrm{AG}_{\mathrm{ref}}\right)$ is used to indicate the degree of titratable acid accumulation $[1,2,13-15]$. As the $A G_{\text {ref, }}$, which is the value of $A G$ without abnormal ions in the serum, we used the average $A G_{\text {adj }}$ of the records with neither acidemia nor alkalemia. Since these records might have had $A G$ disturbances, the value of $A_{\text {ref }}$ used in the present study might not have been appropriate. However, $\triangle \mathrm{AG}$ change by eGFR is independent of the value of 
$A G_{\text {ref. }}$ Thus, titratable acid except lactate would have accumulated in CKD stage G5 as found in the present study, even if $A G_{\text {ref }}$ values were inappropriate.

The present study has several limitations. Firstly, possible inclusion of ketoacidosis, which generally develops irrespective of CKD progression, in high-AGMA could have influenced the development of high-AGMA. However, as mentioned above, this possible inclusion of ketoacidosis would not have influenced the high-AGMA development significantly. Secondly, a limited number of records in a single center, which included only a few records of CKD stage G1 and G2, was analyzed, and the study might be limited by the possibility of selection bias. Thirdly, several samples were from patients receiving multiple medications including diuretics and gastric acid secretion inhibitors. These medications could have influenced the acid-base disturbances that developed in CKD. Thus, further studies with large sample sizes and analyses with measurement of ketones and grouping by differences in treatment are required to confirm the present findings.
To conclude, the present study revealed progression of metabolic acidosis in CKD. High-AGMA other than lactic acidosis develops in CKD stage G5 and progresses by a further decline in renal function at this stage. NonAGMA progresses before the early phase of stage G5 but regresses thereafter.

\section{Statement of Ethics}

The study was approved by the Ethics Committee of the ShinKuki General Hospital.

\section{Disclosure Statement}

The author has no conflicts of interests to declare.

\section{Funding Sources}

There was no funding for the study.

\section{References}

1 Berend K, de Vries AP, Gans RO. Physiological approach to assessment of acid-base disturbances. N Engl J Med. 2014 Oct;371(15): 1434-45.

2 Kraut JA, Nagami GT. The serum anion gap in the evaluation of acid-base disorders: what are its limitations and can its effectiveness be improved? Clin J Am Soc Nephrol. 2013 Nov; 8(11):2018-24.

3 Nagami GT, Hamm LL. Regulation of AcidBase Balance in Chronic Kidney Disease. Adv Chronic Kidney Dis. 2017 Sep;24(5):274-9.

4 Kraut JA, Madias NE. Metabolic Acidosis of CKD: an Update. Am J Kidney Dis. 2016 Feb; 67(2):307-17

5 Hakim RM, Lazarus JM. Biochemical parameters in chronic renal failure. Am J Kidney Dis. 1988 Mar;11(3):238-47.

6 Moranne O, Froissart M, Rossert J, Gauci C, Boffa JJ, Haymann JP, et al.; NephroTest Study Group. Timing of onset of CKD-related metabolic complications. J Am Soc Nephrol. 2009 Jan;20(1):164-71.
7 Abramowitz MK, Hostetter TH, Melamed ML. Lower serum bicarbonate and a higher anion gap are associated with lower cardiorespiratory fitness in young adults. Kidney Int. 2012 May;81(10):1033-42.

8 Abramowitz MK, Hostetter TH, Melamed ML. The serum anion gap is altered in early kidney disease and associates with mortality. Kidney Int. 2012 Sep;82(6):701-9.

9 Phisitkul S, Khanna A, Simoni J, Broglio K, Sheather S, Rajab MH, et al. Amelioration of metabolic acidosis in patients with low GFR reduced kidney endothelin production and kidney injury, and better preserved GFR. Kidney Int. 2010 Apr;77(7):617-23.

10 de Brito-Ashurst I, Varagunam M, Raftery MJ, Yaqoob MM. Bicarbonate supplementation slows progression of CKD and improves nutritional status. J Am Soc Nephrol. 2009 Sep;20(9):2075-84.

11 Widmer B, Gerhardt RE, Harrington JT, Cohen JJ. Serum electrolyte and acid base composition. The influence of graded degrees of chronic renal failure. Arch Intern Med. 1979 Oct;139(10):1099-102.
12 Matsuo S, Imai E, Horio M, Yasuda Y, Tomita K, Nitta K, et al.; Collaborators developing the Japanese equation for estimated GFR. Revised equations for estimated GFR from serum creatinine in Japan. Am J Kidney Dis. 2009 Jun;53(6):982-92.

13 Figge J, Jabor A, Kazda A, Fencl V. Anion gap and hypoalbuminemia. Crit Care Med. 1998 Nov;26(11):1807-10.

14 Carvounis CP, Feinfeld DA. A simple estimate of the effect of the serum albumin level on the anion Gap. Am J Nephrol. 2000 SepOct;20(5):369-72.

15 Feldman M, Soni N, Dickson B. Influence of hypoalbuminemia or hyperalbuminemia on the serum anion gap. J Lab Clin Med. 2005 Dec;146(6):317-20.

16 Kraut JA, Madias NE. Lactic acidosis. N Engl J Med. 2014 Dec;371(24):2309-19.

17 Cahill GF Jr. Ketosis. Kidney Int. 1981 Sep; 20(3):416-25. 